\title{
POLÊMICAS POLÍTICAS, RELIGIOSAS E LITERÁRIAS NO PIAUIi À LUZ DO TRIÂNGULO MIMÉTICO DE GIRARD
}

\section{POLITICAL, RELIGIOUS AND LITERARY POLEMICS IN PIAUÍ BASED ON THE MIMETIC TRIANGLE BY GIRARD}

\author{
Daniel Castello Branco Ciarlini ${ }^{1}$
}

\begin{abstract}
RESUMO: Ao encontrar uma estrutura comum às polêmicas que se desenvolveram em três campos piauienses, o político, o religioso e o literário, este artigo busca compreender as singulares regras e discursos que se operam em suas instâncias, à luz da teoria do triângulo mimético de Girard, que traduzida à realidade brasileira, vale ser observada em complemento à tese do "homem cordial", de Sérgio Buarque de Holanda, e à análise acerca do autoritarismo no Brasil, sintetizado no jargão "sabe com quem está falando?", de que se ocupa DaMatta. A atuação dos protagonistas das contendas é vista tanto nas esferas estética quanto ética, bem como a forma com a qual a linguagem travestida de objetividade migra para uma conduta moral, implicando diretamente em um confronto que invade a subjetividade. Analisam-se casos em cada um desses campos, cujo palco foi as páginas de imprensa, do século XIX às três primeiras décadas do século XX.
\end{abstract}

PALAVRAS-CHAVES: polêmicas; Piauí; triângulo mimético; homem cordial.

ABSTRACT: In finding a structure common to the polemics that have developed in three fields of Piaui - such as political, religious and literary - this article seeks to understand the singular rules and discourses that operates in their instances, using the elucidation of the mimetic triangle theory of Girard, which translated into Brazilian reality, it is worthy of being observed as a complement of the Sérgio Buarque de Holanda's "cordial man" thesis, and also the analysis of authoritarianism in Brazil, synthesized in the jargon "do you know who you're talking to?", which is addressed by DaMatta. The performance of the protagonists of the disputes are seen in both the aesthetic and ethical spheres, as well as the way in which the language transposed by objectivity migrates to a moral conduct, directly implying a confrontation that invades the subjectivity. So, cases are analyzed in each of these fields, whose stage was the press pages, from the nineteenth century to the first three decades of the twentieth century.

KEYWORDS: polemics; Piauí; mimetic triangle; cordial man.

Em pelo menos três campos as polêmicas ocuparam espaço na imprensa piauiense: no político, no religioso e no literário. Têm início no século XIX e mantêm-se ao longo das três

\footnotetext{
${ }^{1}$ Doutorando em Letras (Estudos de Literatura) pela Universidade Federal do Rio Grande do Sul.
} 
primeiras décadas do século XX, quando escasseiam. Percebem-se em cada campo regras próprias e juízos, que admitiam singularidades e serviam de detonadores para contendas. Essa observação não exclui a constatação de que entre eles havia um mecanismo comum, indutor das mudanças de postura, que levava os intelectuais a migrarem da esfera propriamente estética para a ética, resultando em uma transformação radical nos paradigmas postos à prova, bem como no comportamento dos protagonistas, que colocavam de lado certas composturas.

Embora a esfera ética leve aos mesmos discursos nos campos, o mesmo não se dá na estética, operada de modos distintos em cada segmento, apesar de sua postura aparente ou tendenciosamente imparcial e objetiva. A variação, nesse caso, encontra-se nas escolhas de materiais e objetos e nas maneiras com as quais eles são tratados. No campo da polêmica política está relacionada aos sistemas ideológicos, muitas vezes dirigidos por modos a satisfazer certo âmbito social, e cujo fim celebra comportamentos e trato com a coisa pública, próprio de uma estética predominantemente filosófica, alicerçada, no caso brasileiro, em correntes de pensamento advindas da Faculdade de Direito do Recife, promotora do racionalismo científico de escolas como o positivismo, o evolucionismo determinista e o darwinismo social. No campo religioso as discussões giram em torno de uma estética, por assim dizer, hierática, pautada em narrativas que fundamentam a doutrina cristã, baseados em dogmas e catecismo. Já o campo literário, em postura objetal e não moral centraliza a contenda em questões de ordem propriamente material (no caso, vocabular), que aqui têm relação com modos de expressão sintática e, no caso do poema, a problemas de versificação.

Evidentemente os três campos não estão isolados e suas discussões não se concentraram à limitação de suas competências. Há casos da interpenetração de um campo em outro, impulsionada por problemas ligados à conduta moral, comum a todos e que, por ferir uma postura social idealizada e aceita tanto por personagens dos campos como por sua 
audiência, leva as polêmicas aos reclames e ataques de ordem ética. À luz de René Girard, a base dessa operação é o triângulo mimético, constituído por um sujeito e seu modelo, e um objeto. Segundo o teórico, tudo tem início pelo desejo mediado por aquilo que os outros têm ou são, afinal, todo desejo é "mimético", isso quer dizer, "imitativo": "o sujeito desejará o mesmo objeto possuído ou desejado por seu modelo" (GIRARD, 2011, p. 80). Essa equação desacredita um desejo puro, ele será sempre contaminado pela figura de um mediador: "não existe desejo autêntico, e todo desejo é sempre mediado pelos outros” (Idem, p. 78).

Há, porém, nessa inter-relação dois modos específicos que configuram diferentes operações, relacionados à distância temporal e espacial entre sujeito e modelo. Quanto mais afastados no tempo e no espaço estiverem esses dois protagonistas, mais produtivas as suas experiências - é o que Girard denomina de "mediação externa". Quanto menos, próprias da "mediação interna", mais conflituosas, porque sujeito e modelo são iguais e, logicamente, o objeto do modelo acaba acessível ao sujeito. Esse desejo inicial do sujeito não se fixa, na realidade, no objeto em si, mas naquilo que o modelo representa. Em um segundo momento, o desejo mediado já não serve e a atração pelo objeto de fato deixa de ser ideal, instaurando o conflito quando o modelo percebe que a perda do objeto é um risco. Logo, se no primeiro momento o modelo permite que o sujeito acesse o objeto a partir de uma representatividade imposta (ou pelo menos sugerida); em um segundo, o modelo nega o seu acesso, criando o embate. Girard entende que isso pode criar um problema, em que a busca pela posse do objeto leva os adversários a uma contenda na esfera ética, fazendo desaparecer tanto o objeto como confundindo as próprias posições no triângulo, em uma crise que denomina "duplo mimético" ou "rivalidade intensa" - o sujeito "quer tornar-se o Outro sem deixar de ser ele próprio" (GIRARD, 2009, p. 79). Nessa equação, “O sujeito se tornará o modelo de seu modelo, assim como o imitador se tornará o imitador de seu imitador” (GIRARD, 2011, p. 80). 
Resta compreender o objeto que, nos três campos aqui investigados, pode estar relacionado ao prestígio, afinal, em se tratando de um processo conflituoso em que as partes tendem a impor suas capacidades para um público que as assiste - e, por isso, acaba agindo como juiz, capaz de consagrar um vencedor -, o prestígio é o prêmio instituído como valor sociocultural dado tanto a um indivíduo como a um grupo que, ao detê-lo, passa a ter o poder de ditar códigos e fabricar símbolos e, até mesmo, condutas. A busca pelo prestígio, nesse caso, se fundamenta não nele em si, mas nas consequências e nas benesses que ele produz.

Sendo possível pensar em uma estrutura comum recorrente aos três campos investigados, o mesmo se pode fazer do elemento desencadeador do conflito, conformado na mediação interna. Assim, a sua gênese, ou pelo menos o seu disparador, no caso brasileiro, parece residir no que Sérgio Buarque de Holanda, coadunado por João Cezar de Castro Rocha, entende como próprio do "homem cordial”, cuja operação leva o indivíduo a agir mais pelo impulso do que pela razão; daí porque a "Nossa forma ordinária de convívio social é, no fundo, justamente o contrário da polidez" (HOLANDA, 1995, p. 147). O sentimento que sintetiza o seu caráter responde pela "contrariedade" que se relaciona de modo decisivo àquilo que o domina, a emoção e, consequentemente, o impulso. Porque não aceita ser contrariado em suas ideias, projetos e criações, o "homem cordial" costuma levar toda e qualquer questão que o desabone para o lado subjetivo, instaurando um conflito de proporções individuais. A inimizade responde como sentimento legítimo, em que "qualquer discordância no campo das ideias é tomada como um ataque pessoal"' (ROCHA, 1998, p. 166).

Essa questão foi, em algum ponto, também observada por DaMatta, síntese que reside no jargão "Sabe com quem está falando?”, impressa no espírito de uma sociedade altamente hierarquizada como a brasileira, onde se opera uma separação autoritária de posições sociais que podem ser diferenciadas apenas em nível teórico, ou simbólico. Esse conflito que 
responde pela pessoalidade e o anonimato tem como protagonistas os titulares de cargos (que não ocupam mas se apossam dos espaços públicos) e os subordinados; consequentemente opõem-se duas éticas, a "burocrática" e a "pessoal". Logo, os envolvidos "Nunca tomam a expressão como a atualização de valores e princípios estruturais de nossa sociedade, mas sempre como a manifestação de traços pessoais e indesejáveis" (DAMATTA, 1997, p. 185).

É claro que a visada de DaMatta está relacionada a um campo institucionalizado e à presentificação de seus agentes (não necessariamente assistidos por um juiz, a audiência), em que os iguais tendem à anulação; isso, porém, não impede que ela seja vista no campo simbólico, que, levada às páginas de imprensa, define o caráter singular da contenda, por demonstrar uma séria mudança no paradigma ao uso compartilhado da mesma expressão. Assim, esse jargão, por não pertencer a apenas um dos indivíduos (e o conflito se instaura porque os dois lados têm que provar o desnivelamento do adversário), se manifesta quase sempre de modo indireto, diluído em discursos que visam enublar o interlocutor com a exposição de ideias, princípios, teorias, dados ou referências, próprias da fabricação, às vezes artificial, de um perfil erudito. O objetivo, a um só tempo, é desestabilizar o adversário e provar à audiência superioridade, aspirante ou mantenedor do prestígio. À luz de Girard, essa camada de discussão, quando duradora, parece girar em torno da "mediação externa", portanto produtiva, porém perigosamente tendenciosa ao conflito ético, uma vez vencidos os cartuchos da "boa convivência" e das (re)formulações objetivas, que se esgotam porque um dos participantes deixa de sustentar a argumentação e parte para o ataque frontal.

\section{Polêmicas no campo político}

As polêmicas que surgem no campo político piauiense situam-se, em um primeiro momento, no final da primeira metade do século XIX, quando nem mesmo existiam partidos 
políticos na província. Sua origem está ligada diretamente às intrigas de grupos familiares e agregados, em posturas que muito se aproximavam às bases ideológicas de partidos que surgiriam mais tarde, o Liberal e o Conservador. De um lado, o grupo de Manuel de Sousa Martins, que governou por longos vintes anos essas terras e que no ano de 1844, embora não estando no poder, ainda exercia influência sobre parte da província; e de outro lado, as elites formadas especialmente depois desse ano. É o que observa Ana Regina Rêgo:

\begin{abstract}
Mesmo não se denominando de partidos, emergem duas vertentes nítidas, ambas comandadas por oligarquias familiares. De um lado, os Sousa Martins e aparentados, que logo se intitulam Partido Saquarema ou Partido Conservador. De outro, as demais famílias que formam o Partido Urubu ou Partido dos Carrapatos, mais adiante, Partido Liberal (RÊGO, 2001, p. 36).
\end{abstract}

Sob o signo dos interesses familiares, o Piauí assistiu à instauração do regime republicano, que de "republicano" tinha apenas o nome ou as pretensas ações. E aqui, mais uma vez, a tese de Sérgio Buarque de Holanda se aplica, quando a res publica, ou seja, a “coisa pública”, não servia ao bem comum, mas às oligarquias representadas pelos partidos e àqueles que estivessem ligados a elas. Em geral, a estrutura patriarcal, regida pela elite agropastoril, ainda exercia influência sobre os homens que estavam no poder. Nesse quesito, partidos disputavam o "poder pelo poder", e nisso evidenciavam algumas das regras do campo, numa "violência reintegratória", como quer Merquior, que será levada às páginas de imprensa, a fim de se destituir o prestígio conquistado por certo grupo ou indivíduo público. Tal violência, portanto, tem um fundamento: (re)estabelecer privilégios por meio da "coisa pública”, sendo, por isso, "o rosto mau da nossa velha recusa do individualismo igualitário, do nosso tradicional apego ao favor, ao privilégio, ao pistolão" (MERQUIOR, 1981, p. 258).

O prestígio no campo político é construído a partir da expectativa de uma postura libada, reforçada, aqui, por uma instrução formal, geralmente bacharéis em um primeiro 
plano; médicos, engenheiros, farmacêuticos, militares e professores, em um segundo - todos “doutores”, que, na concepção de Gilberto Freyre (1962), substituíam os títulos de comendador, de barão, de visconde e de conselheiro do Império. Em uma sociedade praticamente analfabeta, o "doutor", em alguma medida, exercia sobre a população um efeito positivo: “Seu rosto 'bom' consiste em costume como o paternalismo, o hábito de nossas elites de falar 'pelo' povo, que 'não sabe o que é bom' para si mesmo" (Idem, p. 258). Acontece que essa mesma sociedade era obrigada a conviver com os contrários que existiam dentro da própria elite, que também desejavam as mesmas coisas ou, na fundamentação de Girard, o mesmo objeto - daí a eventual "mediação interna", capaz de fabricar os mais diferentes entraves em nome do ataque e da vingança, cuja manifestação por si mesma, levada a lume nas páginas de imprensa, "transparece um panfletismo agressivo. A virulência prepondera sobre o debate público, não obstante as construções muito bem elaboradas, com riqueza de vocabulário, demonstrando alto conhecimento, não só gramatical, como das ciências e filosofias" (RÊGO, 2001, p. 78).

Assim, os embates, em uma terra de coronéis e doutores que se apropriavam da máquina pública, partiam de grupos antagônicos e entre eles o jargão do "sabe com quem está falando?" que um tentava provar para o outro, baseado, no caso do campo político, em três origens: a da fortuna, a da posição social e do vínculo parental.

Apesar dos ataques, que muitas vezes levavam os intelectuais, sob o anonimato, à troca de insultos e xingamentos, a polidez no discurso, antes disso, também era uma condição para manter a status da persona (LIMA, 1991), bem como a contenda em um nível estético. Não era por acaso que a pretensa elevação no debate, ao uso de figuras retóricas ou no constructo de uma erudição não só primavam pela manutenção do prestígio como visavam, ainda, humilhar um desafeto, que se via obrigado, a fim de sustentar a honra e o caráter, a 
responder à altura. Somente na ausência desse aparelhamento crítico por parte de um adversário é que o embate migrava diretamente para os âmbitos da pessoalidade.

No caso do campo político o prestígio pode ser ainda relacionado às consequências específicas que ele produzia, ou seja, o acesso ao poder, daí a constante refrega existente entre conservadores e liberais, estes travestidos de ideias progressistas à base positivista, em que o combate à ignorância devia ceder ao esclarecimento, à liberdade. Era exatamente nesse terreno que as polêmicas procuravam legitimar discursos a partir de nomes há muito divulgados por Tobias Barreto como Haeckel, Le Bon, Buckle, Darwin, Spencer, Littré etc. Principais promotores dessas ideias no Piaú, Higino Cunha e Clodoaldo Freitas transplantaram para a imprensa o tom polemista. Ora, se o prestígio é um valor atribuído a alguém, e a sua posse permite que esse alguém, por estar legitimado, legitime secundariamente ou mesmo fabrique códigos e os distribua a quem convir, no campo político ele absorve a característica de ser o porta-voz de um todo, o povo. E é em nome dele que suas ações, teoricamente, deveriam se pautar. Não é o que ocorre ao modelo político brasileiro, quando a sociedade está regida pelo "homem cordial”, que “impõe à ordem pública a lógica característica da esfera privada, trazendo para a rua os códigos da casa, por assim dizer" (ROCHA, 2000, p. 222), próprio de uma "formação social caracterizada pela hipertrofia da esfera privada e pelo primado das relações pessoais" (ROCHA, 1998, p. 25).

Dessa forma, como regra a esse campo, pode-se enxergar no dualismo situação e ostracismo a gênese das batalhas no jornalismo piauiense, cujas bandeiras em prol do bem comum, do "povo", encontravam nas posturas e ideologias tanto liberais como conservadoras seus fundamentos. Muito embora, como se tem dito, interesses escusos estivessem regendo as suas atitudes e, consequente, as oposições. Isso se deve porque "no Brasil, vivemos certamente mais a ideologia de ofício e irmandades religiosas, com sua ética de identidade e 
lealdade verticais, do que as éticas horizontais que chegaram com o advento do capitalismo ao mundo ocidental e à nossa sociedade" (DAMATTA, 1997, p. 194-195). A leitura das biografias de Higino Cunha e Clodoaldo Freitas ajuda a entender essa regra. Ambos fizeram da política uma profissão, atuando em cargos por nomeação de chefes políticos a que se vinculavam. Na ausência de uma estrutura partidária que os apadrinhasse, apelavam para o professorado particular ou mesmo para o exercício da advocacia, bacharéis que eram. $\mathrm{O}$ apadrinhamento, no campo político, parece ser a raiz do modo polemista de agir - quanto mais protegidos ou próximos se achavam os polemistas de seus mandatários, maiores eram os efeitos e mais violentos os ataques aos adversários. Esse comportamento tem relação próxima, senão "parental”, ao "sabe com quem está falando?” de Roberto DaMatta, em que o uso do jargão nem sempre está relacionado àquele que detém o poder (no caso do Piauí desse recorte, os coronéis ${ }^{2}$ ) como também àqueles que mantém vínculos com esse detentor.

Assim, os polemistas atuavam na imprensa de modo a angariarem no gesto não apenas agradar aos seus mandatários como também auferirem lucros simbólicos, e se tornarem cooptáveis a futuros regimes ou mesmo aos que lhes haviam negado os cargos públicos. Era esse um dos mais fortes índices da cordialidade piauiense, característica da época, em que "revoltar-se contra o governo do qual se participou, empenhar versos em troca de sinecuras e títulos imperiais ou de cartórios e empregos republicanos são atitudes constantes em uma sociedade órfã de um espaço público fortalecido pela organização efetiva da sociedade civil” (ROCHA, 1998, 72-73).

\section{Polêmicas no campo religioso}

\footnotetext{
${ }^{2}$ Coronéis porque políticos e políticos porque coronéis.
} 
As polêmicas relacionadas ao campo religioso, no Piauí, envolvem padres e maçons. Suas discussões também se dão na imprensa, especialmente em órgãos vinculados à diocese e à maçonaria. $\mathrm{O}$ que está em jogo é, mais uma vez, o prestígio, todavia, o prestígio construído por meio da moral cristã, que os maçons, representando princípios anticlericais e bases científico-filosóficas, procuravam desconstruir.

Sua origem remonta ao ano de 1884 e outra vez está ligada à figura de Clodoaldo Freitas quando, egresso da Faculdade de Direito do Recife, funda, em Teresina, o jornal $O$ Reator, evidenciando em seus editoriais uma postura anticlerical e combativa. No recorte histórico empreendido, diversas foram as folhas que disputaram o prestígio do público, ou pelo menos de sua diminuta elite alfabetizada, como A Época, A Cruz e O Apóstolo, as três vinculadas ao clero; e O Reator, O Oriente, Gazeta do Commercio, O Artista, Litericultura, A Luz e $O$ Monitor, cujos redatores mantinham conexão direta e indireta com a maçonaria.

Clodoaldo Freitas e Abdias Neves respondem como os mais fervorosos opositores da igreja, lançando inúmeros artigos anticlericais em veículos de imprensa por eles fundados ou dirigidos. As temáticas iam de interpretações livres de passagens da Bíblia a questões litigiosas como a separação de casais sacramentados pelo ritual religioso. A esse respeito Abdias Neves é autor de um dos mais violentos ataques ao clero nos primeiros anos do século XX, quando em 1902, à frente do jornal O Artista, produziu argumentos contra a moral religiosa no artigo "Vícios da igreja". Esse texto se opôs à censura dos padres contra aqueles que, uma vez casados no religioso, se separavam e contraíam outro matrimônio à luz das leis do Estado. Neves (1902, p. 2) acusava o argumento dos sacerdotes como "perverso e desumano", pois que visava impedir uma união lícita, diferente da católica, de vez que "casamento, que, para os fins de direito, é como se não existisse"; e justificava que o "sacramento não subsiste como força coatora da liberdade individual, é um simples incidente 
sem valor jurídico" (Idem), ao que concluía, em afronta direta à instituição religiosa: "para os homens de Justiça, a lei é superior a deus e ao céu; ela triunfará para que fique registrado mais um exemplo das misérias que advêm do fanatismo" (Idem).

Já O Apóstolo, que circulou na segunda década do século XX em Teresina, órgão oficial da diocese piauiense, foi o periódico com o maior número de embates do período. Escreviam em suas páginas padres apologetas como João Clementino Mello Lula, Cícero Nunes e Antônio Cardoso de Vasconcelos, que travaram discussões com os mais representativos intelectuais da época.

Em 1912, por exemplo, chama atenção a polêmica entre Clodoaldo Freitas e o padre Mello Lula. A contenda teve início a partir de uma resposta dada pelo clérigo a textos anticlericais assinados por Clodoaldo Freitas na revista Litericultura, que desde o seu primeiro número revelou uma série polêmica sob o título "As tiranias sociais”. Mais tarde, ao discutir o processo que culminou com a condenação de Jesus, o escritor a reconheceu como justa, motivando então a Diocese piauiense a respondê-lo. Por falta de espaço, analisar-se-á aqui apenas o primeiro texto da série comentada, como forma de fundamentar o pensamento antirreligioso de Clodoaldo Freitas, que foi rebatido com uma série assinada por Mello Lula sob o título "Palestras com o bacharel Clodoaldo".

No primeiro texto de "As tiranias sociais", Clodoaldo defende a ideia de que o homem não estava sujeito à liberdade por estar preso a imposições sociais de toda ordem, dentre as quais as religiosas, regidas por “dogmas imutáveis”. A partir de um relato histórico, ilustrado por exemplos, tece as transformações morais dos juízos da igreja, a começar na Idade Média, quando "as torturas faziam parte da penalidade da Inquisição" (FREITAS, 1912, p. 6). Quanto aos seus dias hodiernos, "vemos diariamente o alto e baixo clero atribuir certas calamidades públicas ao castigo da divindade, originado por crimes individuais, pelos pecados populares e 
neste sentido, serem feitas preces públicas e aconselhadas plenitudes gerais” (Idem, p. 7-8), ao que conclui: "A divindade, organizadora da sociedade, nela intervém pelos milagres contínuos, pelos castigos ferozes, pelos benefícios reiterados” (Idem, p. 8). A lógica do crítico era a de que, baseada nesses preceitos, a sociedade se igualava às instituições primitivas e "às que se mantém ou querem se manter no imobilismo" (Idem). E assevera, destacando o papel da moral cristã no modo de vida dos povos:

Os antigos recebiam suas leis diretamente de seu Deus, que era o legislador, o médico, o juiz, o rei e o padre. Nesses preconceitos antigos, da interferência imediata de Deus nos negócios humanos, se prendem a superstição e os milagres, tão triviais nos povos selvagens e entre nós. É preciso render completa homenagem a tudo isto, sob pena de perturbar a harmonia social, ofender a religião e cuspir na moral (Idem).

$\mathrm{O}$ ataque de Clodoaldo à moral católica se prendia, ainda, na ideia de cisão que esta terminou por provocar, representada, de um lado, por liberais que viam na ciência outras interpretações para os problemas humanos, e, de outro, pelos conservadores, que "perseguem os que discrepam desses preceitos seculares, tão respeitáveis quanto ridículos” (Idem). Segue o escritor, procurando desestabilizar o detentor do modelo a partir de uma nova visada acerca do objeto, que durante séculos, nas mãos dos religiosos fora utilizado com "requintes de crueldade" contra o povo. É necessário enfatizar aqui que o "prestígio", no discurso do crítico, está centrado em sua consequência, ou seja, a sua influência:

A sua ação se exerce sobre os povos de costumes, raças e leis diferentes e, por isto, necessita de uma ação constante contra quebra da unidade, que é o segredo da sua força dominadora, exercida inflexivelmente através dos séculos, com um requinte feroz de crueldade (Idem, p. 9).

A defesa elaborada por padre Mello Lula parte exatamente da mesma estratégia adotada por seu adversário, o desmonte da base contrária, no caso expresso pelo clérigo, da moral científica. Para isso, o sacerdote elenca parte dos nomes utilizados pelo pensamento 
científico dos polemistas, que não parecia refutar a religião, mas confirmá-la. Em outras palavras, Mello Lula atirava com a "pólvora alheia", lançando sobre os debatedores maçons a sua própria artilharia. Ao citar Spencer, por exemplo, destaca um trecho do livro Primeiros princípios (1862), em que o estudioso inglês teria afirmado: "todas as conquistas da ciência são conquistas da religião" (SPENCER citado em LULA, 1912, p. 2). O argumento do religioso estava fixado na ideia de provar que a religião católica era "amiga inseparável da verdade científica moderna e que o tão decantado antagonismo entre a fé e a razão nunca existiu, a não ser no cérebro dos sábios de almanaque e dos filósofos sem filosofia" (Idem).

Observa-se que essa polêmica, da parte de Clodoaldo Freitas, se situou na esfera do debate estético, arregimentando de modo específico ideias que foram confrontadas em discurso tecnicamente legitimado. A migração para a esfera ética foi condicionada por padre Mello Lula, em cujo argumento lançava ironias e ataques de ordem pessoal, como a denominação indireta, dada ao escritor, como "sábio de almanaque" e "filósofo sem filosofia".

Não era essa, porém, a primeira vez que o jornal $O$ Apóstolo se posicionaria contra os artigos de maçons. $\mathrm{O}$ caso de Adalberto Peregrino é emblemático em relação às regras que aqui se operaram, impondo na contenda um perfil conflituoso com direito a processo judicial. Ao publicar Ode a satã, em 1907, o mal-estar criado se mostra no referido periódico a partir do título da obra: "Qual a vantagem de se louvar ao espírito das trevas, como lhe chamam as sagradas escrituras?" (FAGUNDES, 1907a, p. 2), que teria escrito L. Fagundes, pseudônimo utilizado pelos clérigos. Soma-se a esse sentimento a conexão do poeta potiguar, que nessa época residia em Teresina, com a maçonaria, desde quando morara no Recife. Além disso, incomodava-se a igreja com o prestígio que a obra ia conquistando no meio teresinense, sendo 
comentada na imprensa. Com o objeto (o prestígio moral cristão) arranhado, era mister o clero se opor e instaurar contenda com o poeta.

Recorrendo à estratégia do anonimato, a Diocese lançou ataques contra a ordem estética e moral de Adalberto Peregrino: "na sua ode, senhor doutor, há muito pus, há muita malícia, muita traição a uma sociedade, como a nossa, que faz da virtude o mais belo apanágio de seu renome" (FAGUNDES, 1907b, p. 3). Ao que consta em rastros deixados no próprio $O$ Apóstolo, às observações estéticas, o potiguar teria respondido no jornal $O$ Comércio, todavia, esses textos não foram encontrados. Sabe-se que a estratégia defensiva do poeta não ferira as estratégias do campo literário, ou seja, mantinham-se articuladas a lições de gramática tomadas em Maximino Maciel, Alfredo Gomes, bem como da Poética de Pinto Bandeira. Quanto aos exemplos, foram os nomes de Camões e de escritores piauienses de renome, como Félix Pacheco e Jonas da Silva, que lhes serviram de apoio.

Se o ataque pessoal é um forte índice da migração de uma contenda das esferas estética (mediação externa) à ética (mediação interna), o tipo de linguagem utilizada nos discursos ajuda a compreender esse processo. No caso do embate anteriormente analisado, quando os protagonistas operam na esfera ética, seus textos perdem a objetividade e adquirem um tom eminentemente coloquial.

\section{Polêmicas no campo literário}

A lógica das polêmicas no campo literário pode ser entendida a partir das ações adotadas por seus protagonistas, ou seja, a adoção de perfis que, uma vez não lhes sendo legítimos, são cooptados de outras áreas. Isso explica porque no terreno das disputas muitos escritores tenham praticado crítica literária e demonstrado conhecimentos filológicos. Por trás desse modo havia um interesse que não difere dos outros campos aqui analisados: mostrar 
erudição e, nela, superioridade, afinal, em termos e questões literárias vence aquele que melhor tiver domínio da língua. Nesse nível de mediação externa, o uso de autoridades tanto literárias quanto filológicas ambicionava tornar certo discurso acusatório ou defensivo legitimado e cumpria demonstrar ao público os exemplos que justificavam a razão dos textos literários, bem como o uso de sua sintaxe.

No Piauí foi Socorro Magalhães (2016) quem, de modo pioneiro, identificou algumas polêmicas literárias travadas nas primeiras décadas do século XX. A pesquisadora elencou três casos: Da Costa e Silva e Benedicto Pestana; Jonathas Baptista e Esmaragdo Freitas; e Adalberto Peregrino e a Diocese Piauiense. Cada um desses casos não difere da lógica que pertence à estrutura do campo polêmico literário, nascidos de questões estéticas, fixaram-se, logo depois, em problemas de ordem ética, com direito a xingamentos, processos judiciais e tentativa de homicídio.

Esses extremos não representam fatos específicos desse campo. Eles ocorrem quando os adversários, em sua luta para impor superioridade, bem como em provar a existência da hierarquia (aqui ligada diretamente às esferas do conhecimento, da erudição), não aceitam as consequências e o desenho inevitável do quadro hierárquico, desestabilizando-o, como também informa DaMatta (1997, p. 214): “a violência no mundo brasileiro é mais um instrumento utilizado quando os outros meios de hierarquizar determinada situação falham irremediavelmente".

Os casos identificados por Socorro Magalhães pertencem a uma das duas lógicas possíveis de interpretação nesse campo, quando cada um dos envolvidos não apenas almeja provar ao público e ao próprio adversário a sua qualidade como também a sua legitimidade como crítico, prestígio-fim do campo em disputa. O interesse em alcançar esse fim é tamanho que as partes do conflito se confundem e obedecem à triangulação mimética de Girard, em 
que o sujeito tenta ser o modelo sem deixar de ser ele mesmo e o modelo enxerga-se sujeito porque a constante (re)formulação dos códigos, por parte de seu adversário, o obriga a posicionar-se nessa condição. Esse fenômeno, impulsionado pela "mediação interna", desvenda um processo de retroalimentação, devido à proximidade tanto física quanto psicológica (ou mesmo simbólica) entre sujeito e modelo. Assim, o que inicialmente era motivado pela vontade de provar superioridade transforma-se em impulso e vingança, e é nesse arriscado conflito que tanto sujeito quanto modelo deixam de lado o objeto (o prestígio), concentrando-se um na aniquilação do outro, sem perceber que se autodestroem perante o público. Daí o motivo de tantos intelectuais terem chegado às vias de fato: "os dois rivais ficam cada vez mais preocupados com a derrota do adversário do que com a obtenção do objeto, que pode se tornar irrelevante, como se fosse apenas uma desculpa para a escalada da disputa" (GIRARD, 2011, p. 80).

No que compete à busca pela erudição em um terreno de disputas, a tese de Holanda ajuda a entender os discursos pomposos como um dos seus traços característicos do homem cordial, que "precisa vestir a farda de teorias enunciadas em alguma 'língua de civilização' [...] quanto mais hermética a formulação, melhor será o resultado" (ROCHA, 1998, p. 191), ou ainda, a sua complexa dualidade de ser muito afável ou extremamente violento, passando do primeiro estágio ao segundo sem quaisquer mediações, e cujo gatilho conflituoso reside no sentimento de superioridade comum aos rivais, que respondem direta ou indiretamente pela deixa do "sabe com quem está falando?".

Se a ideia de "cordialidade" ajuda a entender o que se tem aqui defendido, talvez, no Piauí, em específico neste campo, a contenda envolvendo Da Costa e Silva e Benedicto Pestana seja um exemplo mais nítido. A começar pela relação que esses dois poetas possuíam antes do conflito: ambos surgiram no meio piauiense sob o signo de uma mesma agremiação, 
o "Club Literário 12 de Outubro", dividindo espaço em sua revista, a Andorinha (1906). Mais tarde os dois protagonizariam uma das primeiras polêmicas literárias piauienses do século XX, ao longo da "Seção particular" do jornal Gazeta, mediada por Jonathas Baptista. As estratégias dos dois enunciatários eram diferentes: Pestana dirigia-se ao adversário por meio de "Carta aberta", enquanto Da Costa e Silva, ao uso de uma das estratégias de desconstrução no campo, a ironia, intitulava seus textos a partir de um trocadilho: “A queima das pestanas".

Como era natural, em um primeiro momento a polêmica se manteve na esfera da discussão estética, primando pelo uso correto da língua nas manifestações poéticas. Esgotadas as estratégias discursivas da polidez, os dois poetas migraram radicalmente para a esfera ética, e, à luz da imprensa, passaram a trocar ofensas pessoais, bem como "particularidades da vida privada" (MAGALHÃES, 2016, p. 111). Respondendo à ironia inicial de Da Costa e Silva, Benedicto Pestana, nesse nível de discussão, apela para a mesma ironia: "O teu padrinho zangou-se porque lhe chamei poetazinho. Seria por causa do sufixozinho? Pois bem, para acalmar-lhe a cólera chamar-lhe-ei agora engenhoso poeta. Serve?" (PESTANA citado em MAGALHÃES, 1995, p. 198). Depois de meses o conflito é encerrado com Da Costa e Silva, que lança a sua última sentença: "Previno-lhe que se prepare para um Tribunal de Honra. Estou de partida, mas brevemente aqui estarei. Aconselho-o a ir estudando" (SILVA citado em MAGALHÃES, 1995, p. 199).

Um último caso poderia ser analisado, como segunda interpretação nesse campo. Ele envolveu Amélia de Freitas Beviláqua e Humberto de Campos, no Rio de Janeiro. Diferindo dos demais casos, não havia da parte da escritora a vontade de transcender à mediação interna. A piauiense, na condição de sujeito, enxergava Humberto, o modelo, como crítico e, portanto, detentor dos códigos de consagração. O que almejava, após a publicação de seu livro Impressões, era tão somente ter o seu nome escalado ao cânone seletivo e prestigioso do 
crítico. Ao negar esse acesso, por desacreditar na ascensão intelectual de um nome feminino, o maranhense instaura o conflito, principalmente como se expressa no jornal Correio da Manhã, caracterizando Amélia como superior às demais escritoras brasileiras por ter a qualidade ser esposa de Clóvis Beviláqua. Impressões, portanto, na visão do crítico, não era uma obra, "mas um despretensioso manual do sentimento" (CAMPOS, 1929, p. 2) e um "Livro de amizade e de intimidade, desperta, naturalmente, em que o lê, um sorriso de afetuosa simpatia" (Idem).

A resposta de Amélia se dá nas páginas do Jornal do Brasil, em 5 de abril de 1929. A escritora recorre a dois expedientes, o primeiro, a ironia: "confesso-me criminosa: dei-lhe um livro..." (BEVILÁQUA, 1929, p. 8), e mais adiante, ao tratar da sua desqualificação como escritora, "Para consolo de escrever mal, tenho o Sr. Humberto de Campos. Até agora não fez este livro magistral, que exige dos outros" (Idem); a segunda estratégia de defesa prezava pela legitimidade de seu discurso a partir de vozes autorizadas, e aqui, para mostrar a importância das mulheres na literatura, cita nomes que valiam por si, Mary Ann, George Sand, Mme. de Stäel, Emilla Pardo Bazan, Maria Amalia Vaz de Carvalho, Carolina Michaelis e Júlia Lopes de Almeida. Depois dessa resposta, não há indícios da continuidade dessa polêmica.

\section{REFERÊNCIAS}

BEVILÁQUA, Amélia de Freitas. Carta aberta. Jornal do Brasil, Rio de Janeiro, ano 39, n. 82, p. 8, 5 abr. 1929.

CAMPOS, Humberto de. Amélia de Freitas Beviláqua. Correio da Manhã, Rio de Janeiro, ano 28, n. 10.500, p. 2, 27 mar. 1929.

DAMATTA, Roberto. Carnavais, malandros e heróis: para uma sociologia do dilema brasileiro. 6. ed. Rio de Janeiro: Rocco, 1997.

FAGUNDES, L. Cartas de um velho. O Apóstolo, Teresina, ano 1, n. 18, p. 2, 15 set. 1907a.

FAGUNDES, L. Cartas de um velho. O Apóstolo, Teresina, ano 1, n. 20, p. 3, 29 set. 1907b. FOWLER, Alastair. Gênero y canon literario. In: GARRIDO GALLARDO, Miguel A. (org.). Teoría de los géneros literarios. Tradução de José Simon. Madrid: Arco/Libros, 1988. p. 95-127. 
FREITAS, Clodoaldo. As tiranias sociais. Litericultura, Teresina, ano 1, n. 1, p. 5-11, 1 jan. 1912.

FREYRE, Gilberto. Ordem e progresso. Rio de Janeiro: José Olympio, 1962.

GIRARD, René. Mentira romântica e verdade romanesca. Tradução de Lilia Ledon da Silva. São Paulo: É Realizações, 2009.

GIRARD, René. Evolução e conversão: René Girard, Pierpaolo Antonello, João Cezar de Castro Rocha. Tradução de Bluma Waddington Vilar e Pedro Sette-Câmara. São Paulo: É Realizações, 2011.

HOLANDA, Sérgio Buarque de. Raízes do Brasil. 26. ed. São Paulo: Companhia das Letras, 1995.

LIMA, Luiz Costa. Persona e sujeito ficcional. In: Pensando nos trópicos (demanda II). Rio de Janeiro: Rocco, 1991. p. 40-56.

LULA, Padre Mello. Palestras com o bacharel Clodoaldo: o processo de Jesus. O Apóstolo, ano 6, n. 264, p. 2-3, 11 ago. 1912.

MAGALHÃES, Maria do Socorro Rios. Literatura piauiense: no tempo das polêmicas.

Expressão, Teresina, n. 2, v. 2, p. 195-207, 1995.

MAGALHÃES, Maria do Socorro Rios. Literatura piauiense: horizontes de leitura e crítica literária. 2. ed. Teresina: Academia Piauiense de Letras, 2016.

MERQUIOR, José Guilherme. Sabe com quem está falando? In: MERQUIOR, José Guilherme. As ideias e as formas. Rio de Janeiro: Nova Fronteira, 1981. p. 257-260.

NEVES, Abdias. Vícios da igreja. O Artista, Teresina, ano 1, n. 23, p. 2, 10 ago. 1902.

RÊGO, Ana Regina. Imprensa piauiense: atuação política no século XIX. Teresina:

Fundação Cultural Monsenhor Chaves, 2001.

ROCHA, João Cezar de Castro. O homem de letras (cordial). In: PRIORE, Mary del (org.).

Revisão do Paraíso: os brasileiros e o estado em 500 anos de história. Rio de Janeiro:

Campus, 2000. p. 209-232.

ROCHA, João Cezar de Castro. Literatura e cordialidade: o público e o privado na cultura brasileira. Rio de Janeiro: EdUERJ, 1998.

Recebido em 07/07/2019. Aceito em 09/12/2019. 